\title{
Automation in Collaborative Control over Sharing of Electric Power between Nations Using Genetic Algorithm Based Expert System
}

\author{
G. K. Joshi*, Anil Kumar Sharma,** and Shyam Krishan Joshi***
}

\begin{abstract}
The generation of power is not uniformly distributed allover the globe. The electric power is required to be shared between Nations with and without natural resources to generate power. This however needs collaborative control. It is necessary that the power demand of the sharing Nations should not cause generators to produce power beyond their capacity and also to maintain supply of power within capacity. The paper therefore presents an expert system which fulfills the objective and provides collaborative control over sharing of power, leading to economic and industrial growth of both the countries. Control of power flow through Tie-line has been exercised to meet the objective. The expert system serves to provide rule based control of sharing of powers. It follows an algorithm based control. The control is exercised through regular monitoring of power being supplied from power producing state to non power producing state. It is also being decided by the operational cost of the power generation on the other hand. Efforts have been made to keep this cost minimum using Genetic Algorithm which serves to yield the optimal cost of operation. The proposed model has been tested for real time conditions and is found to have given satisfactory practical results.
\end{abstract}

Key words- Genetic Algorithm, Tie-line power flow, Economic Operations, Reproduction, Crossover and Mutation.

\section{INTRODUCTION}

The requirement of electric power has yet not been fulfilled to even $40 \%$ of its demand all over the globe. Also the natural resources with no harmful effect such as coal, diesel and hydrocarbon gas are depleting. However the perennial resource of water is not spread homogenously over the globe. Also the nuclear power generation cannot be taken up without the scope for dumping of nuclear wastes so as to maintain healthy state of human civilization. Further the generation of power can be abundantly enhanced by developing projects on costal areas, where the tidal power can be harnessed to generate electrical power. So also the hydal power generation can be taken up only across the never depleting rivers of the country. It is therefore in the absence

Manuscript received May 7, 2009 and revised June 23, 2009.

${ }^{*} \mathrm{G}$. K. Joshi is with the Department of Electrical Engineering, at Institute of Engineering and Technology, Alwar-301030, India.

**Anil Kumar Sharma is with the Department of Electronics and Communication Engineering, Institute of Engineering and Technology, Alwar-301030, India.

***Shyam Krishan Joshi is in the Department of Electronics and Communication Engineering, Institute of Engineering and Technology, Alwar-301030,India of uniform distribution of water as natural resource either along the rivers or along the coastal areas, the generation of power cannot be possible in resource less areas of globe. Thus the power generation has to be taken up at areas with plenty of resources, and has to be given to areas, with scantly distributed or no resource point of the globe. The aim of the present paper is to enable sharing of power between Nations with and without natural resources and to obtain collaborative control by way of interchange of power using expert system to monitor the flow of power. An expert system has been developed to monitor the flow of power, such that the generation does not exceed its capacity and the power is utilized by non-power producing Nations. The collaboration between Nations for sharing of electric power would mark agricultural growth, industrial growth \& commercial growth with uplift in the economy of non-power producing countries besides the revenue generation of countries which produce the power. The expert system has been developed on the basis of rules intended to maintain flow of power within given limits, frequency to be constant and operation of generators to be most economical. Further the economic operation of generators has been ensured through Genetic Algorithm.

\section{THE PROBLEM}

To develop automation in enabling collaborative control over sharing of electric power between Nations using expert system, leading to Industrial, agricultural and economic development of both the countries.

\section{THE SOLUTION}

In order to achieve homogenous distribution of electric power/energy despite the naturally but unevenly distributed energy, the transfer of power/energy from power producing countries to non power producing countries is the only solution. Thus the solution lies in developing an expert system which provides automation to flow of power/energy while maintaining the generation within the capability of generators on one hand yet feeding the power demand of non power producing countries. It therefore needs to consider both power supply and power demand and the control strategy to ensure a fool-proof operation in an automated mode. 


\section{TIE-LINE CONTROL}

The proposed strategic controls under various operating conditions are better explained by Tie-line control of power flow between two Nations which are interconnected to share the power, leading to collaborative control over power flow. Consider the Tie-line control for two Nations system.

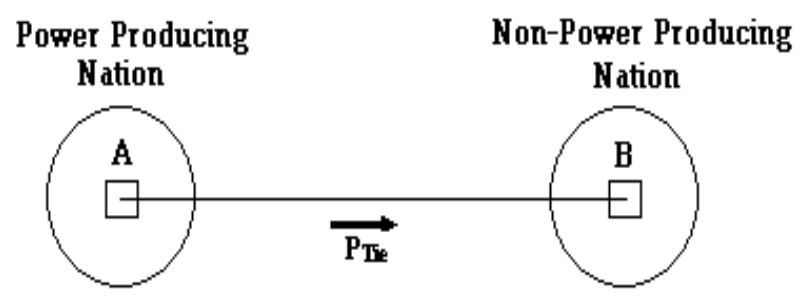

\section{$\Delta \mathrm{P}_{\mathrm{LA}}=$ Load change in Nation-A \\ $\Delta \mathrm{P}_{\mathrm{LB}}=$ Load change in Nation-B}

Fig.1. Tie-line frequency control actions for two Nations

Two utilities are interconnected to enable the transfer of power from power producing Nation to non power producing Nation. This is basically the sell and purchase of power between Nations for economic development of both the countries. Basically Tie-line control is not the selective frequency control. In such a system all the interconnected grids drive their efforts to restore the deviated frequency back to normal, if any one of the grid has failed to help restore frequency.

It is assumed here that no power is received from non power producing Nation-B by Nation-A. Also Nation-A caters all the power demands of Nation-B. Under the condition Nation-A supplies Nation-B after ensuring that $25 \%$ more than its need are taken as no change in the local power demand of Nation-A i.e. change in load of Nation-A are taken as zero $(\triangle \mathrm{PLA}=0)$. Also the changes in load of Nation-B are successfully supplied by Nation-A. Since the changes in load at Nation-B may be either-ive, +ive, or zero accordingly the change in Tie-line power flow will be +ive, -ive or zero respectively and accordingly the $(\Delta \omega) \mathrm{A}$ will be +ive, -ive or zero as shown in Table-1. It also shows the control action to be performed in each case.

Table.I. A summary of the tie-line frequency control scheme

\begin{tabular}{|c|c|c|c|c|}
\hline $\begin{array}{l}\text { Sl. } \\
\text { No. }\end{array}$ & $\begin{array}{c}\text { Change in } \\
\text { Load }\end{array}$ & $\Delta \mathrm{P}_{\mathrm{T}}$ & $(\Delta(0))_{A}$ & $\begin{array}{l}\text { Control Action at } \\
\text { Nation-A }\end{array}$ \\
\hline 1 & $\begin{array}{l}\Delta P_{L_{A}}=0 \\
\Delta P_{L B}=+ \text { ive }\end{array}$ & + ive & - ive & Increase $\left(\mathrm{P}_{\mathrm{Ge}}\right)_{\mathrm{A}}$ \\
\hline 2 & $\begin{array}{l}\Delta P_{L_{A}}=0 \\
\Delta P_{L B}=- \text { ive }\end{array}$ & - ive & + ive & Decrease $\left(P_{G e n}\right)_{A}$ \\
\hline 3 & $\begin{array}{l}\Delta P_{\mathbf{L A}}=0 \\
\Delta P_{\mathbf{L B}}=0\end{array}$ & 0 & 0 & No action \\
\hline
\end{tabular}

PTie $=$ Total actual net interchange of power (+ive indicates power leaving Nation-A \& -ive indicates power entering Nation A)
It is important to point out here that:

1) The increase in load outside the Nation marks the decrease in frequency and increase in net interchange of power leaving the Nation.

2) The increase in load inside the Nation marks the decrease in frequency and decrease in net interchange in power leaving the Nation.

\section{WHAT IS GENETIC ALGORITHM ?}

Genetic Algorithm (GA) is a global search technique based on mechanics of natural selection and genetics. It is general purpose optimization algorithm that is distinguished from conventional optimization by the use of the concept of population genetics to guide the optimum search. A GA operates on a random population of individuals, each representing a solution to the problem at hand. In recent years GA is gaining popularity for its easy searching process, global optimally, independence of searching space and probabilistic nature. GA does its searching process based on its mechanics of natural genetics, instead of point to point search. GA searches from population to population. Each member of population is a randomly selected binary string of definite length called chromosome. New population is evolved from older one through three operations i.e. reproduction, crossover and mutation. Reproduction is the probabilistic selection of two parent strings from the population of strings. The advantages of GA over traditional techniques are; (i) it needs only rough information of the objective function and place no restriction; (ii) The method works with a set of solutions from one generation to the next and not a single solution, thus making it less likely to converge on local minima; (iii) The solutions developed are randomly based on the probability rate of genetic operators such as mutation, and crossover. The initial solutions thus would not dictate the search direction of a GA. Simplicity of operation and the power of the effect (speed and accuracy) are two of the main attractions of genetic algorithms. A simple genetic algorithm that yields good results in many practical problems is composed of three operators i.e. Reproduction, Crossover and Mutation. The disadvantage of GA method is that it requires tremendously high time.

Reproduction is a process in which individual strings are selected according to their objective function value ' $\mathrm{f}$ ' (Biologists call this function-the fitness function). Intuitively, we can think of the function ' $f$ ' as some measure of profit, utility, or goodness that we want to maximize. Selecting strings according to their fitness values means that strings with a higher value have a higher probability of contributing offspring to the next generation. Figure. 3 shows the general flow chart for GA. 


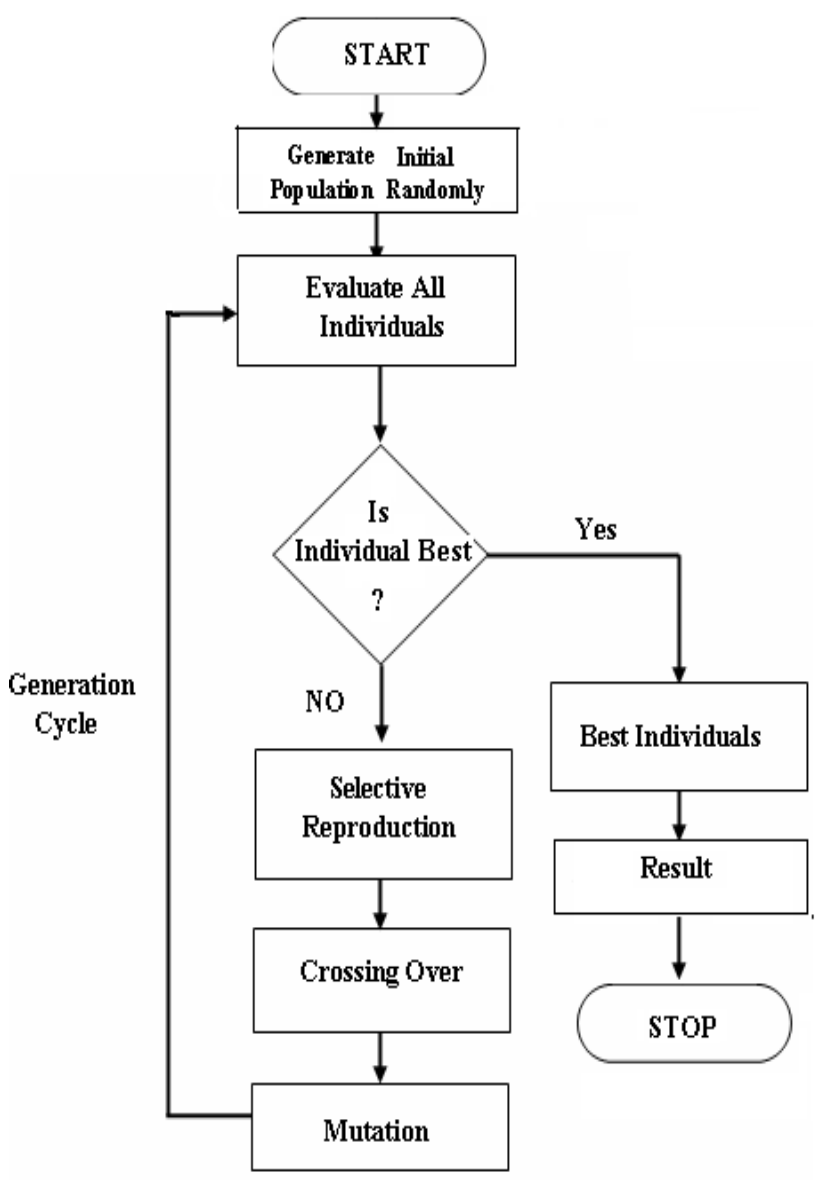

Fig.2. General Flowchart of Genetic Algorithm

Crossover proceeds in two steps. First, members of the newly reproduced strings in the mating pool are mated at random. Second, each pair of strings undergoes crossover as follows: an integer position $\mathrm{k}$ along the string is selected uniformly at random between 1 and the string length less one [1, L-1]. Two new strings are created by swapping all characters between position $\mathrm{k}+1$ and 1 inclusively. Mutation plays a decidedly secondary role in the operation of genetic algorithms.

Mutation is required as despite the fact that reproduction and crossover search and recombine existent notions; occasionally they may lose some potentially useful genetic material. The mutation operation involves periodically selecting one individual at random, selecting one position on the chromosome string and transposing it from 0 to 1 or vice-versa. Mutation restores diversity but does not provide a logical approach to optimization. Its use should be restricted to situations where a local minimum (or maxima) has trapped the algorithm and a new population member is required to trigger the crossover operator on to a better result.

\section{CONSTRAINTS IN AUTOMATION OF POWER TRANSFER}

Technically the transfer of power from one power grid to another power grid requires maintaining following parameters intact viz.

1) Frequency of power supply be maintained constant.

2) Tie-line power be maintained between specified limits.
3) The economic operation of generators be ensured.

The constraint (1) i.e. Maintenance of constant frequency requires to operate generators within their generating capacity. This part is ensured by controlling the throttle of governor by automation, such that the generators operate within their capacity. However in the event of increasing load demand the solution lies in shedding the load rather than increasing the generation.

The constraint (2) is effectively a technique to keep power generation within the rating/capacity of generator. The process used is load bias control. The increased load leads to change the slope of load Vs frequency characteristic as shown in figure3.

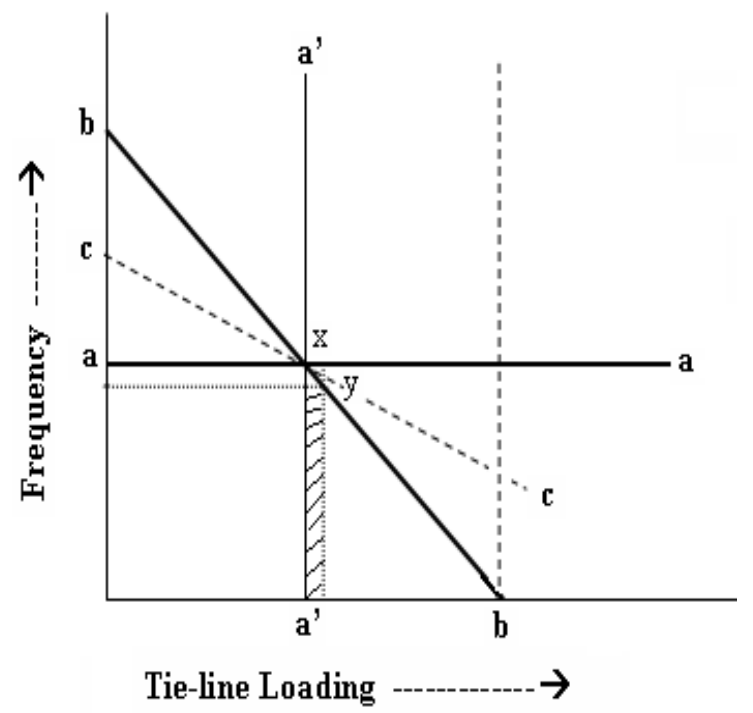

Fig.3. Tie-line loading frequency characteristics

This change in slope leads to change the power demand on the generator which in turn accelerates and increases the power generations. Further the increased power generation restores the deviated frequency back to normal value. Thus load bias control helps in regulating the Ti-line power flow on the one hand and frequency on the other hand. The success in maintaining constraint (2) ensures the success in maintaining constraint (1).

The constraint (3) i.e. economic operation of generators is then achieved using optimal scheduling of generators so that the allocation of loads to all the working units is such that each unit operates economically. This is achieved by using genetic algorithm which ensures perfect allocation of loads at all the moments and operations to the generators causing them to operate at minimum fuel cost i.e. most economically. For this purpose the proper GA has been implemented by developing a computer program.

Accordingly the chromosomes are developed over a successive period of 6 hours i.e. for $1 / 4$ th period of 24 hours or one day. These chromosomes are basically the representation of a string which is nothing but a train of digits which are either 0 or 1 . Here 0 represents the lowest state of generation while the 1 represents the highest state of generation of a particular generator. Also the number of zeros 
and ones in the string are same as the numbers of generating units. The string then undergoes the process of reproduction, crossover and mutation till the best string is achieved.

It is important to point out here that GA approach is the most reliable \& robust one as it does not leave any scope from where the optimization aspect is put to question mark. This is again because the genetic algorithm works on the theory of natural selection and survival of the fittest. The strategic control needed is decided by nature of situation that arises while transferring of power from Nation-A to Nation-B. Further an expert system has been developed which issues commands on the basis of breach of any one of the three constraints, leading to control the parameters such that the automation in collaborative control over sharing of electric power is achieved.

\section{EVOLUTION OF EXPERT SYSTEM}

In order to meet the objective of automation in supplying the power demand to the non power producing Nations such that the generators operate just near their capacity with all the economy. It needs to evolve an expert system. But no expert system works without a rule base. The rule base therefore serves to meet all the requirements. This in turn enables to achieve the target of sharing of the electric power between Nations without breaching the standard operating conditions. The rule base has its roots in the objective of the problem which speaks about sharing of power between Nations while maintaining constant frequency and Tie-line power within limits and also the economic operation of generators. Thus the rules are

Rule-1: If $\Delta \mathrm{P}_{\mathrm{LA}}=0 \& \Delta \mathrm{P}_{\mathrm{LB}}=+$ ive

Then Increase $\left(\mathrm{P}_{\mathrm{Gen}}\right) \mathrm{A}$

Rule-2: If $\Delta \mathrm{P}_{\mathrm{LA}}=0 \& \Delta \mathrm{P}_{\mathrm{LB}}=$ - ive

Then Decrease $\left(\mathrm{P}_{\mathrm{Gen}}\right) \mathrm{A}$

Rule-3: If $\Delta \mathrm{P}_{\mathrm{LA}}=0 \& \Delta \mathrm{P}_{\mathrm{LB}}=0$

Then no change is required.

Rule-4: After implementing control actions the string of generators which is nothing but the states of generators viz. low or high is decided by application of Genetic Algorithm approach. The string as decided by GA is considered to be the operating schedule of generators

Rule-5: If rule- 1 , rule- 2 , rule- 3 \& rule-4 stand satisfied, the sharing of power between Nations is reliable and technically foolproof, otherwise the power sharing ceases to act. The necessary flow chart for control action that works to give the desired output is shown in fig.4.

Table.II. Operational parameters of interconnected power system

\begin{tabular}{|c|c|c|c|c|c|c|c|}
\hline S. Ho. & $\boldsymbol{\omega}_{\text {nom }}$ & $\left(\mathrm{P}_{T 10}\right)_{\text {ranedulied }}$ & $\begin{array}{l}\text { Total } \\
\text { Load } \\
\text { at } \\
\text { nation-A }\end{array}$ & $\left(\mathrm{P}_{\mathrm{T} \mid \mathrm{o}}\right)_{\text {satual }}$ & $\mathbf{A} \mathbf{P}_{\text {La }}$ & $\Delta \mathbf{P}_{\mathrm{IE}}$ & $\boldsymbol{\omega}_{\text {sotusl }}$ \\
\hline $\begin{array}{l}\text { Case-1: } \\
\text { At time: } \\
\text { 14 Hrs. }\end{array}$ & 314.16 & $30 \mathrm{HWH}$ & $300 \mathrm{MWW}$ & 20 MN & 0 & $\begin{array}{l}\text { (+) } 10 \\
\text { MN }\end{array}$ & 289 \\
\hline $\begin{array}{l}\text { Case-2: } \\
\text { At time: } \\
18 \mathrm{Hrs} \text {. }\end{array}$ & 314.16 & $30 \mathrm{MWN}$ & $300 \mathrm{MWN}$ & $20 \mathrm{MNN}$ & 0 & $\begin{array}{l}\text { (-) } 10 \\
\text { MWW }\end{array}$ & 335 \\
\hline
\end{tabular}

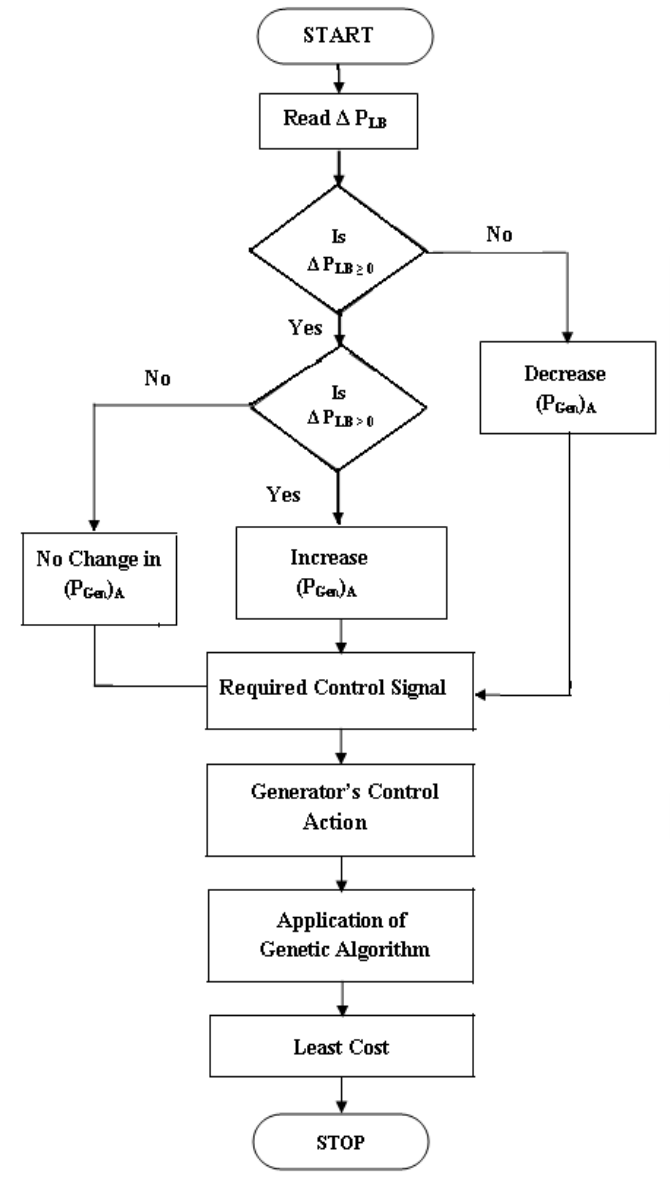

Fig. 4. Flow chart for Control Action

\section{ILLUSTRATION}

Fuel inputs for generators G1, G2, G3 and G4 each of 100 MW of Nation-A are given below

$$
\begin{aligned}
& \mathrm{F} 1=0.2 \mathrm{P} 12+40 \mathrm{P} 1+120 \text { Rs. per hour } \\
& \mathrm{F} 2=0.25 \mathrm{P} 22+30 \mathrm{P} 2+150 \text { Rs. per hour } \\
& \mathrm{F} 3=0.15 \mathrm{P} 32+20 \mathrm{P} 3+135 \mathrm{Rs} \text {. per hour } \\
& \mathrm{F} 4=0.18 \mathrm{P} 42+22 \mathrm{P} 4+150 \text { Rs. per hour }
\end{aligned}
$$

The parameters of generating station of Nation-A are as below. Give control action and cost of economic operation for the two conditions

\section{Case-1: At time: 14 Hrs.}

- Control action suggested: Increase the generation of Nation-A by $10 \mathrm{MW}$.

- $\quad$ Frequency $(\omega)$ changes from 289 to 314.16

- Suggested string of generators' operation as given by GA are 1110 .

- Thus cost of generation Rs. 184948.56 per day.

Case-2: At time: 18 Hrs.

- Control action suggested: Decrease the generation of Nation-A by $10 \mathrm{MW}$.

- Frequency $(\omega)$ changes from 314.16 to 335

- Suggested string of generators' operation as given by GA are 1001 .

- Thus cost of generation Rs. 15349.28 per day.

Thus the conditions keep on changing but the expert 
system issues necessary commands on ensuring that the rule-1 to rule-5 stands satisfied. It therefore enables the success of collaborative control over sharing of power between the Nations.

\section{CONCLUSION}

The efforts made in this work testimonizes that the automation in sharing of power between Nations could be successfully achieved by using expert system which cares for maintaining the supply of load demand within the limits of tie line power flow at standard frequency besides economic operation of generator units. The economic operation of generator units is decided by taking outputs of control actions as inputs to the generating units on one hand and obtaining optimal schedule of operation of generating units over the span of 6 hours taken up successively. The expert system thus proves to be a smart technique for ensuring the collaborative control over sharing of electric power between neighboring Nations. The results obtained show the control strategy and the economic operation of generators using GA.

\section{FUTURE SCOPE}

The problem can be extended to two area systems with both generation and loading conditions existing simultaneously. It needs to enlarge both the basic number of generators and use of GA over the longer sizes of strings (chromosomes). Further the art of developing an expert system is of immense use to the researchers as it can be used as a replacement for human control and can be applied in wide variety of applications for automation techniques.

\section{REFERENCES}

[1] M. L. Kothari, J. Nanda, D.P. Kothari and D.Das, "Discrete-mode Automatic Generation Control of a Two-area R\&at Thermal System with new area control error," IEEE Transactions on Power Systems, Vol.4, No.2, May 1989.

[2] S.A.Kazarlis, A.G. Bakirtzis \& V. Petrdis "A Genetic Algorithm Solution To The Unit Commitment Problem," IEEE Transactions on power Systems, Vol. 11, No. 1, Feb. 1996.

[3] R. K. Green "Transformed Automatic Generation Control", IEEE Transactions on Power Systems, Vol. 11, No. 4, November 1996.

[4] Li Pingkang \& Ma Yongzhen "Some New Concepts in Modem Automatic Generation Control Realization", IEEE Transactions on Power Systems, Vol. 11, No. 4, Nov. 1998.

[5] Jorge Valenzuela \& Alice E. Smith1, "A Seeded Memetic Algorithm for Large Unit Commitment Problems", Journal of Heuristics September 1999.

[6] Esteban Gil, Julian Bustos and Hugh Rudnick, "Short-Term Hydrothermal Generation Scheduling Model Using a Genetic Algorithm" IEEE transactions on power systems, VOL. 18, No. 4, November 2003.

[7] Ignacio Egido, Fidel Fernández-Bernal, Luis Rouco, Eloisa Porras, and Ángel Sáiz-Chicharro, "Modeling of Thermal Generating Units for Automatic Generation Control Purposes", IEEE Transactions On Control Sys. Technology, Vol. 12, No. 1, January 2004.

[8] C.L.Wadhwa, Electrical Power System, New Age International Ltd. Publication, New Delhi, fourth edition-2005, pp-885.

[9] S Arulselvi, Uma Govindrajan, "Real Time Implementation of Modified Fuzzy Logic Controller for a Non-Linear Quasi Resonant DC-Dc Converter,” IETE Journal of Research, vol. 53, No. 5, pp. 401-406, Sep.-Oct. 2007.

Anil Kumar Sharma (MIEEE) received his M.E. degree in Electronics and Communication Engineering from Birla Institute of Technology, Deemed University, Mesra, Ranchi - India, in 2007 with first division (CGPA of 8.45

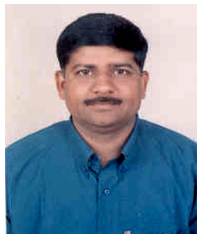

in a 10.00-point scale). He has an experience of 20 years on various type of RADARs and Communication Equipments. He is currently an Assistant Professor in the Department of Electronics and Communication Engineering, Institute of Engineering and Technology, Alwar- 301 030, Rajasthan, India. His research and teaching interest include Microprocessor, RADARs and Data Handling Systems, Neuro-Fuzzy Technique, GA, H.V.D.C Transmission systems and Power Electronics. He is Member of IEEE and Associate Member of The Institution of Engineers (India).

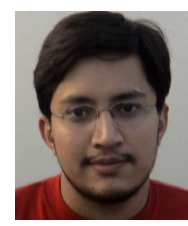

Shyam Krishan Joshi is currently prosecuting his B.E. Electronics \& Communication Engg. Degree in its final phase from IET Alwar under the University of Rajasthan Jaipur, India. His areas of interest are Signals and Systems, Control System Engineering and Genetic Algorithm. His field also extends to undertake projects of public utility. 